\title{
Youth Self-Report Factor Structure: Detecting Sex and Age Differences in Emotional and Behavioral Problems among Spanish School Adolescent Sample
}

\author{
Ihab Zubeidat ${ }^{1}$, Waleed Dallasheh ${ }^{1}$, Antonio Fernández-Parra ${ }^{2}$, Juan Carlos Sierra ${ }^{2}$, José María Salinas ${ }^{2}$ \\ ${ }^{1}$ Sakhnin College Academic College for Teacher Education, Israel \\ ${ }^{2}$ Universidad de Granada, Spain \\ Correspondence: Ihab Zubeidat, Sakhnin College Academic College for Teacher Education, Sakhnin City, 30810, Israel.
}

Received: August 16, 2018

Accepted: September 17, $2018 \quad$ Available online: September 25, 2018

doi:10.11114/ijsss.v6i10.3649

URL: https://doi.org/10.11114/ijsss.v6i10.3649

\begin{abstract}
The Youth Self-Report (YSR/11-18) is a widely used child-report measure that assesses problem behaviors along two "broadband scales": internalizing and externalizing. It also scores eight empirically based syndromes and DSM-oriented scales and provides a summary of total problems. Although the YSR was designed for youths ages 11-18, no studies have systematically evaluated whether youths under the age of 11 can make valid reports using the YSR broad-band, syndrome and DSM-oriented scales. It is a parallel form to the caretaker-completed Child Behavior Checklist (CBCL) and teacher-completed Teacher Report Form (TRF). Few studies related to YSR/11-18 (Achenbach, \& Rescorla, 2000, 2001) factor structure were carried out in Spanish children and adolescent population. This study analyses the factor structure of this assessment tool, in 961 Spanish adolescents attending school from 13 to 18 years old. A principal components method was used to extract the factors followed by a Varimax rotation. According to current research, each sex was treated separately, and only items referred to misbehavior (105 out of 119) were included. Seven first-order common factors were found in both, boys and girls: Anxious/Depressed, Somatic Complaints, Delinquent Behavior, Aggressive Behavior, Attention Problems, Thought Problems and Relational Problems. Factoring of these seven syndromes led to a single second-order factor in younger males. Older males and females showed labeled internalize and externalize symptoms. These results resembled that obtained in former studies with Spanish population.
\end{abstract}

Keywords: youth self report, factor structure, adolescents, internalizing versus externalizing syndromes

\section{Introduction}

The Youth Self-Report for Ages 11-18, YSR11/18) (Achenbach, 1991b) was formed based on the Child Behavior Checklist for Ages 4 to 18 (CBCL/4-18) (Achenbach, 1991c) for the purpose of evaluating psychopathological manifestations (behavior and emotional problems), and psychosocial competencies of children and adolescents aged 11 to 18. The YSR/11-18 can be supplemented with the version addressing parents (CBCL/4-18) and the one for teachers, the Teacher's Report Form for Ages 5 to 18 (TRF/5-18) (Achenbach, 1991a). It is a way of systematically acquiring information on various different competencies and behavior problems in a format similar to the CBCL and the TRF.

\subsection{Composition of the YSR/11-18}

The YSR/11-18 has two parts. The first consists of 17 items and evaluates the psychosocial competencies of young people: participation and success in a variety of activities and social contexts (sports, social and academic skills). The second part has 112 items, of which 16 evaluate pro-social or adaptive behavior, while the rest (96 items) concentrate on problematic behavior.

According to Achenbach (1991b), the problem scales are grouped on two levels. The first consists of the "narrow-band" syndromes (anxiety/depression, isolation, aggressive behavior, etc.) empirically derived from a principal component analysis of the items. The second, "broad-band" level refers to a higher hierarchical structure derived from a second-order factor analysis, which differentiates two general psychopathological patterns, internalizing and externalizing syndromes. Achenbach (1991b) concluded that there are eight self-reported "narrow-band" syndromes that are the same for both sexes: withdrawn, somatic complaints, anxious/depressed (the three comprising the broadband internalizing scale), delinquent behavior, aggressive behavior (the two comprising the broadband externalizing scale), 
social problems, thought problems and attention problems. Some first-order syndromes are considered "mixed", as their factor weight is insufficient for them to be assigned to one of the two broadband syndromes. The YSR/11-18 demonstrated good reliability and validity data in a study by Verhulst, Van der Ende, \& Koot (1997), who reported Cronbach alphas of 0.61 for boys and 0.67 for girls in a sample of a normal population of youths; the highest values were found in clinical samples: 0.73 in boys $(0.73)$ and 0.70 in girls. In a French population, the YSR/11-18 scales were highly correlated, the Cronbach alpha coefficient for them varied from 0.83 to 0.92 and the test-retest correlations were robust (Wyss, Voelker, Cornock, \& Hakim-Larson, 2003). In United States, results demonstrated that younger youths were able to provide reliable reports on the YSR broad-band (Internalizing, Externalizing) scales, though less so on the narrow-band scales. Across all scales, the externalizing scales performed more favorably than the internalizing scales among both younger and older youth (Ebesutani, Bernstein, Martinez, Chorpita, \& Weisz, 2011). Despite the fact that the Youth Self-Report has been used in many studies throughout the world, little is known about the equivalence of the factor structure of this measurement for immigrant adolescents. In this line, Verhulp, Stevens, van de Schoot, \& Vollebergh (2014) reported that the scales of the YSR/11-18 were invariant across al ethnic groups (native Dutch, Surinamese, Turkish and Moroccan) and over time. Together, the results indicated that this instrument can be used for developmental studies in these immigrant populations.

\subsection{Validation of the YSR/11-18 in Spanish Population}

The YSR/11-18 was validated in the general Spanish population by Lemos, Fidalgo, Calvo, \& Menéndez (1992a, 1992b, 1992c). In the first study (Lemos et al., 1992a), the girls had high scores in internalizing behavior (anxious/depressed and somatic complaints), while the boys had higher externalizing scores (socially maladaptive and aggressive behavior). Furthermore, the scores for problem behavior in Spanish adolescents were higher than those found in European and American adolescents. Similar results were found in the study by Achenbach (1991b), in which the greater tendency of girls to internalize problems and of men to externalize them is consistent with the information provided by parents and teachers. Lemos et al. (1992a) reported four internalizing factors, of which three were given the same name for both sexes (Anxious/Depressed, Somatic Complaints and Relational Problems), while the fourth factor (Anxious) was specific to boys. They also found four externalizing factors, three of which were common to boys and girls (Delinquent behavior, Attention Seeking and Aggressive Behavior) and one specific to boys (Antisocial behavior). The factor Thought problems was the only one identified in the mixed syndrome. Abad, Forns, Amador, \& Martorell (2000) analyzed the version used by Lemos et al. (1992a), reporting that the internal consistence was more homogeneous and higher for the internalizing and externalizing syndromes than for the narrow-band. Furthermore, the internalizing syndrome showed covariation with the Krug Clinical Analysis Questionnaire (CAQ) Depressed and Psychological maladjustment scales to the contrary, no consistent pattern has been demonstrated in the relationship between the externalizing syndrome and the CAQ. There is therefore a more consistent pattern in the relationship between the internalizing than the externalizing syndrome and neuroticism and anxiety measurements with regard to other scales (Abad et al., 2000). The third Lemos et al. study (1992c) reported a pattern of positive correlations between the internalizing syndrome and the Eysenck Personality Questionnaire-Junior Neuroticism scale. The externalizing syndrome is correlated with all of the scales (mainly with Psychoticism, Antisocial Behavior and Sincerity), except Extraversion.

The Lemos, Vallejo, \& Sandoval study (2002) derived eight main syndromes different from those found by Achenbach (1991b): depressed, verbal aggressive, delinquent behavior, thought problems, somatic complaints, social relations problems (isolation), attention seeking and phobic-anxious behavior. Moreover, two second-order factors were found to pertain to internalizing and externalizing psychopathology (emotional vs. behavioral disorders). Posteriorly, Sandoval, Lemos, \& Vallejo (2006) aimed to provide a standardization of self-reported competences and emotional/behavioral problems in Spanish adolescents, using the Achenbach's Youth Self-Report. The YSR was completed by 2822 adolescents aged 11-18 years, recruited from secondary schools in two regions of Spain. There were significant differences in total behavior problems and in most problem scales in boys and girls, scoring boys higher on externalizing syndromes, whereas girls score higher on internalizing syndromes. Males' mean scores were higher than females' scores for social competence. Age effects also showed significant differences with respect to internalizing problems, thought problems, social problems and depression. To test the overall range of variations across cultures, comparisons were made between broad band and narrow band measures of the YSR in Spanish adolescents and those from other countries. Gender differences in the YSR were similar to those found across different cultures; there is a consistent trend to increase behavioral problems with age; and social competence seem to be a relevant protective factor against behavioral problems. In this line, Kirchner, Forns, \& Amador (2006) reported that girls' scores increased on delinquent and aggressive behavior scales and, therefore on externalizing scores, while the boys' scores increased on attention problems and delinquent behavior and decreased on anxious/depressed, social problems' and internalizing scores. In addition, the test-retest intra-class correlations for the broad-band scales ranged between 0.62 (internalizing) 
and 0.68 (externalizing) and for the narrow-band scales between 0.37 and 0.67 . In other study, with the objective to study the incremental validity of the DSM-Oriented scales of the YSR/11-18, Lacalle, Domènech, Granero, \& Ezpeleta (2014) found that the oriented scales showed significant incremental validity in conjunction with the empirical syndromes scales for discriminating DSM-IV (American Psychiatric Association, 2000) diagnoses, and considerable incremental validity in conjunction with the diagnoses obtained throw the diagnostic interview for predicting the level of functional impairment.

In order to diagnose a "behavioral disorder", the last update of the Diagnostic and Statistical Manual of Mental Disorders, fifth edition (DSM-5, American Psychiatric Association, 2014) suggests having carried out in the past 12 months at least three of the following behaviors: 1) aggression towards people or animals: bullying, intimidation, threats, fights, physical cruelty, rape...; 2) deliberate destruction of others' property; 3) cheating or theft: lying, cheating, stealing...; 4) severe breach of rules: forging notes, truancy, going out at night without permission.

\subsection{Modifications and Several Uses of the YSR/11-18}

Achenbach and Rescorla $(2000,2001)$ modified the YSR/11-18, editing some of the items and changing the number corresponding to problematic and pro-social behavior, leading to a different version from Achenbach (1991b). This new version also has two parts. The first consists of 17 items referring to different psychosocial competencies, such as sports, social and academic skills, while the second is made up of 112 items, of which 14 describe adaptive or pro-social behavior and the remaining 98 measure problem behavior (actually 105 items, since Item 56 is divided into 8 sub-items referring to physical problems having no known medical cause). Achenbach, Dumenci, \& Rescorla (2001), after having combined some categories that coincided with DSM criteria, also constructed scales for the following categories: affective problems, anxiety problems, somatic problems, attention/hyperactive problems, oppositional/defiant problems and behavior problems.

Achenbach (1978) founded an evaluation and diagnostic system known by the initials ASEBA (Achenbach System of Empirically Based Assessment). The studies done by Achenbach and his colleagues to date have led to a problematic or pathological behavior classification system for children and adolescents, and another for related diagnosis. The YSR/11-18 is included in this classification system. The YSR/11-18 (Achenbach, 1991b) has been widely used in clinical practice and in psychopathological research due to its usefulness in establishing a quantitative taxonomy. In the last decade, this measurement was used in different populations in order to explore distinct objectives such as investigate which YSR/11-18 items or scales can be used best to predict anxiety disorders in adolescents (Ferdinand, 2007), determine its contribution in the diagnosis of psychiatric comorbidity of juvenile primary headache disorders (Toros et al., 2010), examine emotional and behavioral problems among school adolescents with and without reading difficulties as measured by the YSR/11-18 (Undheim, Wichstrom, \& Sund, 2011), test the measurement invariance of the attention and thought problems subscales in a population-based sample of adolescents with and without epilepsy (Ferro, Boyle, Scott, \& Dingle, 2014), examine the relationship between weight and psychological distress in Hispanic with excess weight (Yates et al., 2014), detect mental health problems in children's and adolescents in residential care (Sainero, del Valle, \& Bravo, 2015), examine the prevalence and characteristics of the dysregulation profile of adolescents based on data from the YSR/11-18 (Jordan, Rescorla, Althoff, \& Achenbach, 2016), investigate to what extent emotional and behavioral problems impact on and explain the academic performance of adolescents (Rosso, \& Helena, 2017), and identified population-representative youth surveys containing questions on self-reported child maltreatment (Laurin, Wallace, Draca, Aterman, \& Tonmyr, 2018).

\subsection{Social, Cultural and Spanish School and Family Contextualization Model}

Socialization is a process by which humans acquire the values, beliefs, norms and forms of proper behaviour of the culture to which they belong (Musitu, \& Cava, 2001). The main goal of this process is for one to take the socially valued objectives as guiding principles of his own conduct, ie, get him take as his own a set of internally consistent values that will become a filter for evaluating the acceptability of his behavior (Musitu, \& Cava, 2001). Therefore, the periods of childhood and adolescence are critical in this process and, consequently, family has been considered a particularly privileged place for the transmission of these cultural categories. In fact, social scientists have given special attention to the family socialization over the past few decades. An essential aspect in the study of family socialization process has been its effect on personality and adjustment of children and adolescents. We must not forget that child socialization is the primary responsibility in most societies. Thus, within the processes of family interaction, those that aim to socialize the child in a certain system of values, norms and beliefs occupy a major part. These socialization processes are undoubtedly part of the most widely recognized family functions; in fact, it's around socialization where the family roles are distributed and the expectations and parent-child behaviors are delimited. In this sense, it is possible to claim that socialization is perhaps the cornerstone of family life. The socialization process continues at school, whereas children and adolescents not only acquire new contents, values and standards that prepare them for adulthood, 
but also create new relationships with peers and establish relations of friendship and companionship (Cava, \& Musitu, 2002; Martínez, 2013). Additionally, the school is the first formal contact with authority figures. In this scenario, one of the problems that concerns most of the teachers, as well as families and professional intervention, is school violence.

Parents, relevant socialization agents, represent culture, explicitly or implicitly transmitting social values to their sons and daughters. Family context has considerable influence on the development of social behavior, and there is much empirical evidence confirming if parents: 1) provide a safe feeling of attachment, 2) strongly insist that their children should not harm others, 3) make them repair the harm when they have hurt and/or attacked others, 4) are altruistic models in their relations with others, 5) reinforce through social approval their children's spontaneous acts of sharing, helping, or cooperating, and 6) adopt a style of inductive discipline from which they discuss the rules, this increases the probability of the emergence of prosocial behavior in their children (see Garaigordobil, 2003, 2008). Family is the main socializing agent and has therefore received much attention by researchers. The influence of variables such as the family structure, cohesion, the presence of conflicts, parenting styles...was explored with regard to the psychological, social, and emotional adjustment of the children. In the same vein, the present study analyzes the connections between antisocial behavior and family contextual variables such as parents' level of acceptance-involvement and coercion-imposition, as well as the educational or socialization styles used by the mothers and fathers with their sons and daughters.

Traditionally, studies about parenting socialization have first analyzed how parents teach their children and then the effect that this socialization generates in the various aspects of their lives of children. Overall, in the history of the studies on this theme, scholars have identified the existence of two main dimensions: Acceptance/Involvement and Severity/Imposition (Barber, Chadwick, \& Oerter, 1992; Foxcroft, \& Lowe, 1991; Smetana, 1995). However, many other labels, were associated with these dimensions: Symonds (1939) labeled them as Acceptance/Dominance; Baldwin (1955), Involvement/Hostility; Becker (1964), Affection/Restriction; Sears, Maccoby and Levin (1957), Affection/Strictness; and, Schaefer (1959), Love/Control. For example, Linares, Rusillo, de la Torre Cruz, de la Villa Carpio Fernández, \& Arias (2011) reported, in Spanish sample composed by 469 secondary school students (aged between 12 and 18), that the adolescents presented differences in perception of the educational practices of both parents as a function of their gender. Negative parenting practices were positively related to adolescents' internalizing and externalizing problems, whereas positive practices were negatively related to externalizing problems. Moreover, differences between boys and girls were found in predictor variables of problems, and the predictive power of the variables was higher for externalizing problems.

One can better understand these dimensions when considered according to a Cartesian coordinates where the X-axis represents the acceptance/Involvement dimension related to those parenting practices connected with the use of warmth, dialogue and understanding of the behavior of the children. The positive aspect of this axis relates to the more frequent use of this kind of practice and the negative one to the less frequent. The axis of the ordinates, on its turn, represents the Strictness/Imposition dimension, characterized by the use of coercive practices used in the control of the behavior of children, i.e., parents who resort to verbal and physical punishment to control the behavior of their children. In connection with this dimension, the positive aspect of the axis of the ordinates - Y-axis - is related to the repeated use of this sort of practice by parents and the negative one to the rare or no use at all of them.

Literature comparing the relations between the styles of parenting socialization and variables related to the psychological and psychosocial adjustment of children have found different pattern of results between different cultural context. The traditional studies carried out with Anglo-Saxon cultures indicate that children of authoritative parents show better psychological and psychosocial adjustment than children whose parents resort to other styles (Baumrind, 1991; Chao, 2001; Christian, 2002; Steinberg, Lamborn, Dornbusch, \& Darling, 1992). This result, however, does not cover other cultural contexts such as American families of Asian or African origins (Dornbusch, Ritter, Liederman, Roberts, \& Fraleigh, 1987; Steinberg, Mounts, Lamborn, \& Dornbusch, 1991). Furthermore, the studies carried out within Spanish and Italian cultural contexts concluded that the use of an indulgent style of socialization promoted a better psychological and psychosocial adjustment of the children than the use of an authoritative style (DiMaggio, \& Zappulla, 2014; Fuentes, García, Gracia, \& Alarcón, 2015).

\subsection{Rationale and Importance of Research}

The majority of the studies done in Spanish and North American adolescent populations have used the Achenbach (1991b) version of the YSR/11-18, as mentioned above. In fact, this instrument has been translated into 59 languages and led to over 300 studies, of which some have attempted to determine its factor structure. However, to date, few studies have used the Achenbach, \& Rescorla $(2000,2001)$ version of the YSR/11-18, especially for factor analysis (Ivanova et al., 2007; Lambert, Essau, Schmitt, \& Samms-Vaughan, 2007; O'Keefe, Mennen, \& Lane, 2006). The few publications on the version of these authors indicates the need for this instrumental study (Carretero-Dios, \& Pérez, 
2007; Montero, \& León, 2007) in a sample of Spanish school-age adolescents in order to clarify its factor structure and examine the relationships existing among the various factors found in both sexes. The study also examines differences between young and old adolescents in internalize and externalize symptoms of the Youth Self-Report.

\section{Methodology}

\subsection{Participants}

The sample was made up of 961 young secondary school students in the Province of Granada (Spain) selected by incidental sampling, of which 412 were boys $(42.90 \%)$ and 549 were girls $(57.10 \%)$, aged 13 to $18(M=15.63 ; S D=$ 1.32). Approximately two thirds of the adolescents $(n=652 ; 67.80 \%)$ were in 2nd, 3rd and 4th year of Obligatory Secondary Education (middle school); the rest were in Bachillerato (high school) $(n=174 ; 18.10 \%)$ and other occupational education courses $(n=135 ; 14 \%)$, such as hotel and restaurant, hairdressing, cooking, etc.

\subsection{Instrument and Procedure}

The 9-01 version of the YSR/11-18 by Achenbach, \& Rescorla (2000, 2001), translated by the Autonomous University of Barcelona Unitat d'Epidemiologia i Diagnòstic en Psicopatologia del Desenvolupament, was given at 13 schools. Written consent was requested of professors and parents of underage adolescents. The data was collected during tutoring classes. The evaluation of the adolescents was always controlled by the same person, who in all cases was the one responsible for providing the instructions and directions for answering the questionnaires, which ensured that they were the same across the entire sample. It was given collectively and anonymously in a single session approximately 60 minutes long. 15 youths who did not agree to the evaluation and 9 others who left without finishing were excluded from the study.

\subsection{Analysis of Results}

The SPSS statistical package, version 12.0 was used for all of the analyses. Of the 112 items on the YSR/11-18 (actually 119 because Item 56 includes 8 sub-items) only 105 items that describe problem behavior were selected for later analysis to derive first and second-order syndromes. 14 items $(6,15,49,59,60,73,80,88,92,98,106,107,108$ and 109) that refer to desirable social behavior were omitted from the analysis as proposed by Achenbach, \& Rescorla (2001). These items are not saturated in the first-order syndromes, but all of them are saturated in the same factor alluding to desirable social behavior. It was therefore decided to eliminate them from the factor analysis. The idea is to subject the problem emotional and behavior items to factor analysis, extracting the factors by principal components with varimax rotation to derive the first-order syndromes for each sex. The main syndromes were found later by extraction from the factor structure common to samples of both boys and girls. The methodology used by Achenbach (1991a) and Achenbach, \& Rescorla (2001) was taken into consideration as much as possible for this to attempt to replicate the factors found in the population of American youths, following the steps below:

1. Factor analysis of the correlations matrix for the items for each sex using the principal components method

2. Varimax rotation of 7, 8,9 and 10 components for the male sample and 7, 8 and 9 components for girls.

3. Select the rotation providing the set of items that tends to concur, most theoretically coherent.

4. Derive the main symptoms from the items common to both sexes and to main syndromes.

5. Calculate correlations between first-order syndromes separately for each sex and between main syndromes.

6. Principal components analysis of the above correlation matrices.

7. Varimax rotation of the components found.

\section{Findings}

Principal components factor extraction applied to the correlations matrix of 105 problem items on the YSR/11-18, found 33 and 29 factors with eigenvalues over 1, explaining $64.88 \%$ and $61.459 \%$, respectively, of the total variance in data for the samples of boys and girls. Then the highest factors (7, 8, 9 and 10 factors for boys and 7, 8 and 9 factors for girls) were subjected to orthogonal rotation (Varimax), where the rotation converged at 16, 19 and 21 iterations for the first and at 10 and 19 iterations for the second. The seven principal components found in the male and female samples, their eigenvalues, and variance explained are shown in Table 1. 
Table 1. Factor structure for boys and girls. Only those factors with eigenvalues over 3 are included (N=961)

\begin{tabular}{|c|c|c|c|c|c|c|c|}
\hline $\begin{array}{c}\text { Factor } \\
\text { Boys }\end{array}$ & Category & Eigenvalue & $\begin{array}{l}\text { Variance } \\
\text { explained }\end{array}$ & $\begin{array}{c}\text { Factor } \\
\text { Girls }\end{array}$ & Category & Eigenvalue & $\begin{array}{l}\text { Variance } \\
\text { explained }\end{array}$ \\
\hline 1 & $\begin{array}{l}\text { Anxious/ } \\
\text { depressed }\end{array}$ & 5.21 & 4.96 & 1 & $\begin{array}{l}\text { Anxious/ } \\
\text { depressed }\end{array}$ & 6.05 & 5.76 \\
\hline 2 & $\begin{array}{l}\text { Aggressive } \\
\text { behavior }\end{array}$ & 5.14 & 4.89 & 2 & $\begin{array}{l}\text { Aggressive } \\
\text { behavior }\end{array}$ & 5.74 & 5.46 \\
\hline 3 & Somatic complaints & 5.04 & 4.80 & 3 & Somatic complaints & 5.46 & 5.20 \\
\hline 4 & $\begin{array}{l}\text { Delinquent } \\
\text { behavior }\end{array}$ & 4.40 & 4.19 & 4 & Attention problems & 5.45 & 5.19 \\
\hline 5 & Thought problems & 4.03 & 3.83 & 5 & $\begin{array}{l}\text { Delinquent } \\
\text { behavior }\end{array}$ & 4.43 & 4.22 \\
\hline 6 & Attention problems & 3.79 & 3.61 & 6 & Thought problems & 4.30 & 3.09 \\
\hline 7 & Relations problems & 3 & 2.84 & 7 & Relations problems & 3.73 & 3.56 \\
\hline
\end{tabular}

Total variance explained: Boys $=29.15 \%$; Girls $=32.51 \%$

Variance explained in the space defined by the factors: Boys $=64.88 \%$; Girls $=61.45 \%$

As shown in Table 1, the factor structure of the two samples is identical, with seven factors with eigenvalues over 3. Within the two factor structures, the categories anxious/depressed, aggressive behavior, somatic complaints and relational problems appear in first, second, third and seventh place. The two structures differ in the specific weight of three categories: delinquent behavior, thought problems and attention problems, appearing in fourth, fifth and sixth place for boys and in fifth, sixth and fourth place for girls.

The different categories assigned to the factors found were determined by analyzing the content of the items that saturate each. That is, each cluster of items under a certain factor describes problem behavior that defines a theoretical category. Factors were thus labeled according to the theoretical content of their items. Items over 0.30 are considered saturated, while those that were under this were eliminated, since they would explain less than $10 \%$ of the factor variance. Along this line, Comrey (1985) argues that 0.30 is a reasonable value for its use for orthogonal factor weights. Tables 2 and 3 show the items with weights of 0.30 or over which make up the first-order syndromes for boys and girls, respectively.

Table 2. First-order syndromes, derived by Varimax for boys $(\mathrm{N}=412)$

\begin{tabular}{|c|c|c|c|c|c|}
\hline & Anxious/depressed & & & Attention problems & \\
\hline Item & $\overline{\text { Description }}$ & Weight & Item & $\overline{\text { Description }}$ & Weight \\
\hline 35 & Low self-esteem & 0.54 & 8 & Can't concentrate/pay attention & 0.58 \\
\hline 38 & Laughed at & 0.51 & 5 & Doesn't enjoy many things & 0.57 \\
\hline 33 & Feels unloved & 0.49 & 4 & Doesn't finish things & 0.51 \\
\hline 31 & Afraid to do something wrong & 0.49 & 13 & Gets distracted & 0.48 \\
\hline 34 & Ideas about persecution & 0.48 & 61 & Low school performance & 0.44 \\
\hline 103 & Unhappy and depressed & 0.46 & 10 & Hard to sit still & 0.33 \\
\hline 50 & Anxious or afraid & 0.45 & 9 & Hard to not think about anything & 0.33 \\
\hline 52 & Guilty & 0.42 & 78 & Attention deficit/distracted & 0.32 \\
\hline 29 & Fears & 0.41 & & & \\
\hline 27 & Jealous & 0.40 & & $\underline{\text { Delinquent behavior }}$ & \\
\hline 11 & Depends on adults & 0.37 & Item & $\overline{\text { Description }}$ & Weight \\
\hline 32 & Perfectionist & 0.35 & 23 & Disobedience at school & 0.62 \\
\hline 12 & Lonely & 0.33 & 28 & Rule-breaking & 0.58 \\
\hline 48 & Believes he is not accepted & 0.32 & 22 & Disobeys parents & 0.55 \\
\hline 112 & Worried & 0.31 & 26 & Does not feel guilty & 0.44 \\
\hline \multirow[t]{3}{*}{14} & Crying & 0.30 & 39 & Problem relations & 0.40 \\
\hline & & & 25 & Doesn't get along well with others & 0.38 \\
\hline & $\underline{\text { Aggressive behavior }}$ & & 19 & Tries to get attention & 0.35 \\
\hline Item & Description & Weight & 21 & Property destruction & 0.33 \\
\hline 93 & Talks to much & 0.60 & 57 & Hitting others & 0.32 \\
\hline 90 & Dirty language & 0.54 & 16 & Treats others badly & 0.31 \\
\hline 94 & Likes to be annoying & 0.49 & 74 & Attention seeking & 0.30 \\
\hline 45 & Nervous or tense & 0.49 & & & \\
\hline 68 & Shouts a lot & 0.46 & & $\underline{\text { Thought problems }}$ & \\
\hline 95 & Strong character & 0.46 & Item & $\overline{\text { Description }}$ & Weight \\
\hline 104 & Raises his voice & 0.44 & 84 & Strange behavior & 0.429 \\
\hline 96 & Thinks too much about sex & 0.44 & 85 & Strange thoughts & 0.394 \\
\hline 41 & Does things without thinking & 0.42 & 91 & Thinks about killing himself & 0.366 \\
\hline 97 & Threatens & 0.38 & 40 & Hears nonexistent sounds & 0.346 \\
\hline 87 & Moody & 0.33 & 110 & Wishes he were the opposite sex & 0.331 \\
\hline 86 & Stubborn & 0.32 & 66 & Repetitive behavior & 0.317 \\
\hline 43 & Lies/cheats & 0.30 & & & \\
\hline
\end{tabular}




\begin{tabular}{|c|c|c|c|c|c|}
\hline & Somatic complaints & & & Social relations problems & \\
\hline Item & Description & Weight & Item & Description & Weight \\
\hline $56 \mathrm{~g}$ & Vomiting & 0.68 & 75 & Shy & 0.675 \\
\hline $56 \mathrm{c}$ & Nausea & 0.65 & 71 & Insecure & 0.613 \\
\hline $56 a$ & Pain or discomfort & 0.62 & 69 & Reserved attitude & 0.524 \\
\hline $56 f$ & Stomachaches & 0.59 & 77 & Sleeps more than others & 0.504 \\
\hline $56 b$ & Headaches & 0.58 & 65 & Refuses to speak & 0.366 \\
\hline 51 & Dizziness & 0.51 & 79 & Speech problems & 0.324 \\
\hline $56 \mathrm{~d}$ & Eyes bother him & 0.47 & & & \\
\hline $56 \mathrm{~h}$ & Other somatic complaints & 0.45 & & & \\
\hline 58 & Scratches himself & 0.40 & & & \\
\hline $56 \mathrm{e}$ & Skin problems & 0.39 & & & \\
\hline 46 & Jerking & 0.39 & & & \\
\hline 54 & Exhaustion & 0.33 & & & \\
\hline 53 & Eats too much & 0.30 & & & \\
\hline
\end{tabular}

Table 3. First-order syndromes, derived by varimax for girls $(\mathrm{N}=549)$

\begin{tabular}{|c|c|c|c|c|c|}
\hline & Anxious/depressed & & & Delinquent behavior & \\
\hline Ítem & Description & Weight & Item & Description & Weight \\
\hline 33 & Feels unloved & 0.69 & 28 & Rule-breaking & 0.67 \\
\hline 35 & Low self-esteem & 0.66 & 22 & Disobeys parents & 0.61 \\
\hline 12 & Lonely & 0.64 & 23 & Disobedient at school & 0.60 \\
\hline 34 & Ideas about persecution & 0.52 & 21 & Property destruction & 0.49 \\
\hline 38 & Laughed at & 0.49 & 25 & Doesn't get along well with others & 0.41 \\
\hline 32 & Perfectionist & 0.48 & 19 & Tries to get attention & 0.37 \\
\hline 18 & Attempted suicide & 0.48 & 43 & Lies or cheats & 0.37 \\
\hline 103 & Unhappy and depressed & 0.48 & 26 & Does not feel guilty & 0.37 \\
\hline 27 & Jealous & 0.45 & 39 & Problematic relations & 0.37 \\
\hline 14 & Crying & 0.43 & 20 & Property destruction & 0.35 \\
\hline 31 & Afraid to do something wrong & 0.40 & 37 & Fights & 0.30 \\
\hline 30 & Afraid to go to school & 0.40 & & & \\
\hline 24 & Malnutrition & 0.36 & & Thought problems & \\
\hline 36 & Self-destructive & 0.33 & Item & $\overline{\text { Description }}$ & Weight \\
\hline 112 & Worried & 0.31 & 70 & Sees things that do not exist & 0.56 \\
\hline 62 & Clumsy. uncoordinated & 0.30 & 85 & Thinks strange thoughts & 0.51 \\
\hline & & & 84 & Strange behavior & 0.48 \\
\hline & $\underline{\text { Somatic complaints }}$ & & 40 & Hears nonexistent sounds & 0.35 \\
\hline Ítem & $\overline{\text { Description }}$ & Weight & 61 & Low school performance & 0.34 \\
\hline $56 \mathrm{~g}$ & Vomiting & 0.65 & 7 & Boasts, conceited, braggart & 0.30 \\
\hline $56 \mathrm{c}$ & Nausea & 0.64 & & & \\
\hline $56 f$ & Stomachaches & 0.62 & & Attention problems & \\
\hline $56 a$ & Pain or discomfort & 0.61 & Item & $\overline{\text { Description }}$ & Weight \\
\hline $56 \mathrm{e}$ & Skin problems & 0.57 & 78 & Attention deficit, distracted & 0.55 \\
\hline 58 & Scratches herself & 0.57 & 10 & Hard to sit still & 0.50 \\
\hline $56 \mathrm{~h}$ & Other somatic complaints & 0.56 & 68 & Shouts a lot & 0.49 \\
\hline $56 b$ & Headaches & 0.55 & 45 & Nervous or tense & 0.49 \\
\hline 51 & Dizziness & 0.52 & 93 & Talks too much & 0.48 \\
\hline 54 & Exhaustion & 0.47 & 13 & Absentminded & 0.44 \\
\hline 55 & Overweight & 0.34 & 41 & Does things without thinking & 0.44 \\
\hline & & & 83 & Keep useless things & 0.40 \\
\hline & Aggressive behavior & & 74 & Seek Attention & 0.38 \\
\hline Ítem & Description & Weight & 8 & Can't concentrate / pay attention & 0.36 \\
\hline 105 & Consumes alcohol or drugs & 0.62 & 9 & Hard to think not about anything & 0.31 \\
\hline 97 & Threats & 0.59 & & & \\
\hline 101 & Cuts class. absence & 0.57 & & $\underline{\text { Relations problems }}$ & \\
\hline 94 & Likes to be annoying & 0.54 & Item & $\overline{\text { Description }}$ & Weight \\
\hline 99 & Smokes cigarettes & 0.52 & 75 & Shy & $0.65^{\circ}$ \\
\hline 96 & Thinks too much about sex & 0.51 & 69 & Reserved attitude & 0.63 \\
\hline 90 & Dirty language & 0.47 & 71 & Feels ashamed. ridiculous & 0.57 \\
\hline 89 & Distrustful & 0.46 & 65 & Refuses to talk & 0.45 \\
\hline 91 & Thinks about killing herself & 0.44 & 79 & Speech problems & 0.39 \\
\hline 104 & Raises her voice & 0.44 & 50 & Anxious or afraid & 0.39 \\
\hline 2 & Drinks without permission & 0.43 & 77 & Sleeps more than others & 0.33 \\
\hline 110 & Wishes she were opposite sex & 0.41 & 102 & Lacks energy & 0.31 \\
\hline 95 & Strong character & 0.40 & & & \\
\hline 16 & Treats others badly & 0.31 & & & \\
\hline 87 & Moody & 0.31 & & & \\
\hline
\end{tabular}

As shown in Table 2, in the male sample, Item 10 (Hard to sit still) had a factor weight of 0.44 in the category "aggressive 
behavior" and another of 0.33 in attention problems, although it was included in the second because of its content. Thus, Items 12 (Loneliness), 14 (Crying) and 32 (Perfectionism) had factor weights of $0.52,0.37$ and 0.41 in the categories "attention problems", "somatic complaints" and "delinquent behavior", respectively, and others of $0.33,0.30$ and 0.35 , respectively in the category "anxious/depressed", where they were included because of their content. Even though Item 18 (Suicide attempts) showed factor weights of $0.32,0.34$ and 0.37 in the categories "somatic complaints", "thought problems" and "attention problems", respectively, it was not included in any of these three categories because it did not coincide with their content. Items 21 (Property destruction), 57 (Hitting others) and 74 (Attention seeking) also showed factor weights of $0.33,0.32$ and 0.30 , respectively, and were considered in the category "delinquent behavior", even though it had weights of $0.49,0.37$ and 0.44 in the "somatic complaints" and "social relations problems" categories, respectively. Item 78 (Lack of attention, distracted) had factor weights of $0.36,0.32$ and 0.37 in the "delinquent behavior" and "thought problems" categories, and were included in the second because they coincided with its content.

As shown in Table 4, in the sample of girls, Item 24 (Malnutrition) had factor weights of 0.36 and 0.40 in the categories "anxious/depressed" and "delinquent behavior", respectively, and was included in the first because it coincided with the content. Similarly, Item 37 (Fights) had factor weights of 0.30 and 0.35 in the "delinquent behavior" and "thought problems" categories, respectively, and was considered in the first because the content coincided. Finally, Item 102 (Lack of energy) showed factor weights of 0.31 and 0.42 in the "relational problems" and aggressive behavior" categories, respectively, and was included in the first because of the coincidence in content. In this way, and as shown in Tables 2 and 3 , the number of items that saturated with over 0.30 in the seven categories labeled varied in the samples of boys and girls. The seven categories, "anxious/depressed", "aggressive behavior", "somatic complaints", "attention problems", delinquent behavior", "thought problems" and "relational problems" clustered 16,13,13, 8, 11, 6 and 6 items, respectively for boys and 16,15,11,11,11, 6 and 8 items for girls.

Table 4. Main syndromes for boys and girls $(\mathrm{N}=961)$

\begin{tabular}{|c|c|c|c|}
\hline & Anxious/depressed & & Aggressive behavior \\
\hline Item & Description & Item & Description \\
\hline 12 & Loneliness & 87 & Moody \\
\hline 14 & Crying & 90 & Dirty language \\
\hline 27 & Jealous & 94 & Likes to annoy \\
\hline 32 & Perfectionist & 95 & Strong character \\
\hline 33 & Feels unloved & 96 & Thinks too much about sex \\
\hline 34 & Ideas of persecution & 97 & Threatens \\
\hline 35 & Low self-esteem & 104 & Raises his/her voice \\
\hline 38 & Laughed at & & \\
\hline 103 & Unhappy, depressed & & Attention problems \\
\hline \multirow[t]{3}{*}{112} & Worried & Item & Description \\
\hline & & 8 & Lack of concentration/attention \\
\hline & Somatic complaints & 9 & Hard to not think of anything \\
\hline Item & Description & 10 & Hard to sit still \\
\hline 51 & Dizziness & 13 & Absentminded \\
\hline 54 & Exhaustion & 17 & Daydreamer \\
\hline $56 a$ & Pain or discomfort & 78 & Attention deficit, distracted \\
\hline $56 \mathrm{~b}$ & Headaches & & \\
\hline $56 \mathrm{c}$ & Nausea & & Thought problems \\
\hline $56 \mathrm{e}$ & Skin problems & Item & $\overline{\text { Description }}$ \\
\hline $56 f$ & Stomachaches & 40 & Hears nonexistent sounds \\
\hline $56 \mathrm{~g}$ & Vomiting & 84 & Strange behavior \\
\hline $56 \mathrm{~h}$ & Other somatic complaints & 85 & Strange thoughts \\
\hline \multirow[t]{3}{*}{58} & Scratching her/himself & & \\
\hline & & & $\underline{\text { Social relations problems }}$ \\
\hline & Delinquent behavior & Item & Description \\
\hline Item & $\overline{\text { Description }}$ & 65 & Refuses to speak \\
\hline 19 & Tries to get attention & 69 & Reserved attitude \\
\hline 21 & Property destruction & 71 & Feels ashamed or ridiculous \\
\hline 22 & Disobeys parents & 75 & Shy \\
\hline 23 & Disobedient at school & 77 & Sleeps more than others \\
\hline 25 & Doesn't get along with others & 79 & Speech problems \\
\hline 26 & Does not feel guilty & & \\
\hline 28 & Rule-breaker & & \\
\hline 39 & Problematic relations & & \\
\hline
\end{tabular}

Once the factor structures for the two samples had been found, and the first-order syndromes assigned, the main syndromes were derived. For the nature of the syndromes found to be considered the same in both samples, at least $50 \%$ of their items had to be common to them. Each main syndrome was comprised of the common items that concur in the same 
category in the two samples. As a result, the seven main syndromes, common to both samples ("anxiety/depressed", "somatic complaints", "delinquent behavior", "aggressive behavior", "attention problems", "thought problems" and "relational problems") included a total of $10,10,8,7,5,3$ and 6 items, respectively, sharing $62.50 \%, 83.33 \%, 72.72 \%$, $50 \%, 52.63 \%, 50 \%$ and $85.71 \%$ of common items, respectively. Table 4 describes the seven main syndromes that include the items common to both samples of girls and boys.

Then the additive scales were found separately for both samples, for the main syndromes and first-order (sum of the raw scores for each subject on the different items that make up the factor) and to calculate the correlation matrices existing between the scales for boys, girls and the total. Table 5 shows the descriptive statistics for girls and boys for the first-order syndromes.

Table 5. Descriptive first-order syndrome statistics for boys and girls $(\mathrm{N}=961)$

\begin{tabular}{lccc}
\hline Syndromes & Boys $M(S D)$ & Girls $M(S D)$ & Main $M(S D)$ \\
\hline Anxious/depressed & $6.81(5.01)$ & $6.26(4.53)$ & $4.34(3.45)$ \\
Aggressive behavior & $2.04(4.49)$ & $7.52(4.92)$ & $4.28(2.73)$ \\
Somatic complaints & $3.56(3.66)$ & $3.07(3.39)$ & $2.70(3.05)$ \\
Attention problems & $5.78(3.06)$ & $8.58(4.09)$ & $4.69(2.63)$ \\
Delinquent behavior & $3.71(3.19)$ & $3.67(3.16)$ & $2.78(2.54)$ \\
Thought problems & $1.49(1.80)$ & $1.95(1.78)$ & $0.71(1.14)$ \\
Relational problems & $3.45(2.59)$ & $3.89(2.82)$ & $3.02(2.30)$ \\
\hline
\end{tabular}

As shown in Table 5, the averages of first-order syndromes in the sample of boys varied from $(\mathrm{M}=1.49$; $\mathrm{SD}=1.80)$ in Thought problems to $(M=6.81 ; \mathrm{SD}=5.01)$ in Anxious/depressed. Averages of the first-order syndromes in the sample of girls varied from $(M=1.95 ; S D=1.78)$ in Thought problems to $(M=8.58 ; S D=4.09)$ in Attention problems. Finally, total sample averages among the first-order syndromes varied from $(\mathrm{M}=0.71 ; \mathrm{SD}=1.14)$ in Thought problems to $(\mathrm{M}=$ 4.69; $\mathrm{SD}=2.63$ ) in Attention problems.

Results also show that the correlations between first-order syndromes in the sample of boys varied from $(\mathrm{r}=0.09 ; \mathrm{p}<$ $0.001)$ (between Relational problems and Thought problems) and ( $\mathrm{r}=0.56 ; \mathrm{p}<0.001)$ (between Delinquent behavior and Aggressive behavior) and $(\mathrm{r}=0.59 ; \mathrm{p}<0.001)$ between Attention problems and Somatic complaints). Correlations between the first-order syndromes in the sample of girls varied from $(r=0.11 ; p<0.001)$ (between Social Relational problems and Delinquent behavior) to $(\mathrm{r}=0.59 ; \mathrm{p}<0.001)$ (between Attention problems and Somatic complaints). Finally, total sample correlations among the first-order syndromes varied from $(r=0.09 ; \mathrm{p}<0.001)$ (between Relational problems and Thought problems) and $(r=0.48 ; \mathrm{p}<0.001)$ (between Attention problems and Anxious/depressed).

Finally, as shown in Table 6, a second-order factor analysis was done for both samples of boys and girls and for the total, using the same methodology described above, applying the principal component methods for extracting factors and using varimax rotation on them. Table 6 shows the results for the second-order factor analysis for boys, girls and total. As shown, both younger boys (from 13 to 15) and the total had a single factor, made up of the seven first-order categories, explaining $49.77 \%$ and $43.25 \%$ of the total variance, respectively. The contrary is true of older boys (16 to 18 years old) who have two factors explaining 58.44\% of the total variance, referring to internal symptomology (anxious/depressed, somatic complaints and relational problems) and external (aggressive behavior, attention problems, delinquent behavior and thought problems). Thus girls basically had two factors that explain $63.68 \%$ of the total variance and reflect separation of internalizing syndromes (anxious/depressed, somatic complaints and relation problems) and externalizing (aggressive behavior, attention problems, delinquent behavior and thought problems).

Table 6. Second-order factor analysis for boys, girls and total

\begin{tabular}{|c|c|c|c|c|c|c|}
\hline $\begin{array}{l}\text { Second } \\
\text { syndromes }\end{array}$ & $\begin{array}{l}\text { First } \\
\text { syndromes }\end{array}$ & $(n=207)$ & $(n=549)$ & $\begin{array}{l}\text { First } \\
\text { syndromes }\end{array}$ & $(n=205)$ & $(n=961)$ \\
\hline & Two factors & $\begin{array}{l}\text { Boys } \\
\text { (ages } \\
16-18)\end{array}$ & $\begin{array}{c}\text { Girls } \\
\text { (ages } \\
13-18 \text { ) }\end{array}$ & Single factor & $\begin{array}{l}\text { Boys } \\
\text { (Ages } \\
13-15) \\
\end{array}$ & $\begin{array}{c}\text { Total } \\
\text { (Ages } \\
13-18 \text { ) }\end{array}$ \\
\hline \multirow{4}{*}{ Internalizing } & & Weights & Weights & & Weights & Weights \\
\hline & Anxious/depressed & 0.72 & 0.69 & Anxious/depressed & 0.79 & 0.73 \\
\hline & Somatic complaints & 0.52 & 0.61 & Somatic complaints & 0.70 & 0.63 \\
\hline & Social relations p. & 0.86 & 0.88 & Aggressive b. & 0.76 & 0.68 \\
\hline \multirow{4}{*}{ Externalizing } & Aggressive $b$. & 0.77 & 0.79 & Delinquent $\mathrm{b}$. & 0.75 & 0.69 \\
\hline & Attention problems & 0.54 & 0.68 & Thought problems & 0.66 & 0.52 \\
\hline & Delinquent $\mathrm{b}$. & 0.73 & 0.76 & Relational problems & 0.45 & 0.52 \\
\hline & Thought problems & 0.70 & 0.73 & & & \\
\hline $\begin{array}{l}\text { Total } \\
\text { explained }\end{array}$ & & $58.44 \%$ & $63.68 \%$ & & $49.77 \%$ & $43.25 \%$ \\
\hline
\end{tabular}




\section{Discussion and Conclusions}

The purpose of this study is to explore the factor structure of the Achenbach, \& Rescorla $(2000,2001)$ version of the YSR/11-18 in a sample of Spanish adolescents. All of the analyses were done separately for the samples of boys and girls to demonstrate the similarities and differences in the factor structure as well as to derive the main syndromes common to both sexes. To do this, a factor analysis of the 105 items on problem behavior in the YSR/11-18 was done to find the least number of categories or factors that reproduce the correlations between them, as argued by Harman (1980). The 14 items on socially adaptive behavior were excluded from the analysis because they form a clear factor referring to socially desirable behavior (Achenbach, \& Rescorla, 2000, 2001). The specific factor extraction technique used to derive the syndrome categories that tend to concur in the two samples was the principal components method.

The similarity in content of the seven factors found in the samples of boys and girls could be due to the high homogeneity of the participants in the study, as they were all adolescents between 13 and 18 years of age attending school in the province of Granada (Spain). The first three factors (Anxious/depressed, Aggressive behavior and Somatic complaints) appear in the same order in both samples due to their eigenvalues and the variance they explain. In the fourth place is Delinquent behavior for the boys and Attention problems for the girls. In fifth place, we find Thought problems for boys and Delinquent behavior for girls. The six place is taken by Attention problems and Thought problems for boys and girls, respectively. The last was the Social relations factor for both sexes.

From these seven categories, the following main syndromes common to both sexes were derived: Anxious/Depressed, Somatic complaints, Delinquent behavior, Aggressive behavior, Attention problems, Thought problems and Relational problems. These factors were derived by including the items that concur in the same category for both samples. There are few studies concerned with clarifying the factor structure of the YSR/11-18. One of them is Achenbach (1991a) in which he concluded that there were eight narrow-band "main syndromes" the same for both sexes: Withdrawn, Somatic complaints, Anxious/Depressed (the three comprising the broadband internalizing scale), Delinquent behavior, Aggressive behavior (the two comprising the narrow-band externalizing scale), Social problems, Thought problems and Attention problems. In spite of the different origin of the samples of adolescents used, both in our study and in Achenbach's (1991b), six of the main syndromes coincide: Somatic complaints, Anxious/Depressed, Delinquent behavior, Aggressive behavior, Thought problems and Attention problems.

In Spain, Lemos et al. (1992a) reported seven factors for girls similar to those found by us and nine for boys. In addition to the seven categories found in this study, they considered another two categories (Antisocial behavior and Anxiety). Moreover, six of the seven main syndromes (Anxious/depressed, Somatic complaints, Aggressive behavior, Delinquent behavior, Thought problems and Relational Problems) derived in the work of these authors had names similar to those used by us, and many of the items coincided. The seventh category name (Attention seeking) and item content were different from the one found in this study (Attention problems). The results found by Lemos et al. (1992a) may be considered very similar to ours, which may be due to the similarity in the characteristics of the samples of adolescents attending school used in both studies. The slight differences in results between the two studies may be due to the use of different versions of the YSR/11-18. While the Lemos et al. (1992a) study used the Achenbach (1991b) version of the YSR/11-18, this study used the Achenbach and Rescorla $(2000,2001)$ version.

In another study done by Lemos et al. (2002) with the Achenbach (1991a) version of the YSR/11-18, eight main syndromes were derived (Depressed, Oral aggressive, Delinquent behavior, Thought problems, Somatic complaints, Social relations problems, Attention seeking and Phobic-anxious behavior) from the nine first-order factors derived for both sexes. Only three main syndromes (Delinquent behavior, Thought problems and Somatic complaints) coincide with those found in our study. The rest of the syndrome names and contents of the items clustered were different from those reported by us. It should be pointed out that the sample used in the Lemos et al. (2002) study was mostly (2.529) made up of students from 11 to 18 years of age at many public primary and secondary schools in Asturias, while the remaining 304 adolescents were from four secondary schools in the Region of Madrid. The sample is therefore more heterogeneous than the one selected by us, which could explain the differences found in the results of the two studies, added to the fact that different versions of the YSR/11-18 were found as mentioned. Another recent studies (Kirchner et al., 2006; Lacalle et al., 2014; Sainero et al., 2015; Yates et al., 2014), that used the YSR/11-18 measurement in Spanish populations, had distinct objectives than those ones established in the studies of Lemos et al. (2002a, 2002b, 2002c), and related to the factor structure of this instrument.

In this context, the YSR/11-18 was used in some international studies. In Mexico, García, \& Palos (2005) found that the factors in the Achenbach, \& Rescorla $(2000,2001)$ version hold in the Mexican version of the YSR/11-18, although there are some differences. While in the Mexican version there are 6 factors, one for externalizing problems and 5 for internalizing problems, in the original YSR/11.18, there are 5 scales, three subscales for Internalizing problems, one for Social problems, one for Thought problems; one for Attention problems and two subscales for Externalizing problems. In 
Portugal, Cruz, Narciso, Pereira, \& Sampaio (2014) used a short form of Portuguese version of the YSR/11-18, where the findings confirmed that the YSR short form provides a good fit to the data, explains similarly the variance on several criteria compared with the longer version, and is sensitive to sex and age differences. In Ethiopia, Geibel et al. (2016) found that across the eight syndrome scales, the YSR best measured the diagnosis of anxiety /depression and social problems among young women, and attention problems among young men, concluding that the YSR has enough reliability and validity in identifying young vulnerable women and men with the mentioned problems.

Our second-order factor analysis results showed that, older boys (16-18) and girls, showed two factors corresponding to a separation between internalizing syndromes (Anxious/depressed, somatic complaints and relational problems) and externalizing (Aggressive behavior, Attention problems, Delinquent behavior and Thought problems). These two second-order factors referring to internalizing vs. externalizing psychopathology could allude to a separation between emotional and behavioral disorders, respectively, as defended by Lemos et al. (1992a, 2002). Paradoxically, our study demonstrates that both older boys and girls had similar internalizing and externalizing psychopathologies, contrary to findings by González, \& Cueto (2000), who observed that girls had a different internalizing pathology from the externalizing pathology reported by boys. Also, the younger boys (13-15 years old) in contrast to the older boys had a single factor encompassing the seven main syndromes that we found. It was found that the correlations between the different scales of the YSR/11-18 for girls and boys were similar but slightly higher for girls on anxious/depressed and thought problems (Kirchner et al., 2006). Also, in another study effectuated in a sample of 138 young Spanish people aged from 11 to 18 who were in residential care, results show low and moderate levels of concordance between the information given by the young people and their educators, with higher levels of agreement in externalized problems, in a similar way as the results found in research with samples of parents and children (Sainero et al., 2015). In recent study, the evaluation of adolescents, families and teachers shows that attention problems explain low school performance, in addition to the externalizing of problems indicated by the adolescents and the isolation or depression indicated by the teachers (Rosso, \& Helena, 2017).

Finally, socialization processes have been a theme of utmost interest to psychology. As through those individuals acquire notions about social regulation, which allows them to adapt to the culture pertaining them. Besides playing an important role in psychosocial adjustment, socialization is present in the vast psychology literature, which indicates a meaningful connection between socialization and psychological adjustment. In the first socialization individuals get in touch with, probably the principal ones related to the internalization of social norms and patterns, occur within the family, and parents are the main agents of socialization. This socialization extends throughout adolescence and its effects will be present in the behavioral repertoire of each individual in the course of his lifetime (Baumrind, 1971, 1983; Lewis, 1981). In Spain, according to the General Attorney, the total number of complaints has doubled in the past five years, from just under 2,500 to more than 5,000 cases in 2010. Ibabe and Jaureguizar (2010) provide data from the Basque Country that set the child-to-parent violence percentages between 13\% and 25\%, and, in a later study (Ibabe, \& Jaureguizar, 2011), they found that $21 \%$ of boys and girls participating had used physical violence against their parents, another $21 \%$ had used psychological violence (verbal) and half of them (46\%) had used emotional violence (blackmail). Also, Van Der Ende, \& Verhulst (2005) found that adolescents reported higher levels of problems than parents and teachers for all types of behavior. Parents reported higher levels of problem behavior than teachers. Gender differences among informants were dependent on type of problem behavior. With increasing age, scores of adolescents, parents, and teachers diverged for most types of problems, with larger differences for older adolescents than for younger adolescents. Norms for adolescents need age adjustments for reports by adolescents, parents, and teachers.

Related to the socialization process, In Andalusia, Zubeidat, Fernández-Parra, Sierra, \& Salinas (2008) revealed that the factors associated with anxiety and social phobia is a subject of recent interest in mental health. Specifically, shyness in children seems to act as an early expression of social phobia that may later consolidate into a clinical entity. The presence of certain psychopathologies and particular styles of child rearing in parents, are perceived by their children, are associated with the emergence of social phobia in adolescence. On the other hand, social anxiety disorder during adolescence or early adulthood may predict subsequent depressive disorders. The presence of both disorders (anxiety and social phobia) during adolescence increases the probability of suffering from them recurrently in early adulthood. Family structure and cohesion as well as stressful life events have been found to be associated with mood disorders during the childhood-youth period. However, studies conducted with young subjects are scarce, even though understanding the factors associated to different psychopathologies in the youth has proven of great value in clinical practice and epidemiology. For this reason, the researchers attempt to evaluate, in a sample of three groups of adolescents (social anxiety, other psychopathologies and without psychopathologies) the possible demographical factors, competences and clinical indexes that could be associated with the different conditions under consideration. The results of this study indicated thet sex and couple relationships significantly affect the probability of manifesting social anxiety and other psychopathologies in adolescents, respectively. Some competences significantly affect the probability of developing 
social anxiety, whereas others affect the probability of developing other psychopathologies. The majority of the 46 clinical indexes assessed in the present study demonstrate a significant effect on the probability of developing both conditions. Also, Zubeidat, Fernández-Parra, Sierra, Vallejo, \& Ortega (2009) analyzed the psychosocial competences and psychopathological characteristics assessed by the YSR/11-18 in a sample of Spanish adolescents from 13-18 years. The results indicated that men scored high in various social activities and externalized psychopathologies, while women have high scores for performance in different tasks and internalized symptoms. Younger adolescents showed higher scores than older ones in participation in groups and organizations, as well as in most of the YSR/11-18 syndromic scales, while older adolescents preferred no sports activities and works or tasks. Students at Compulsory Secondary Education and Non-Compulsory Secondary Education showed more activity than those in Vocational Training Cycles in all psychosocial competencies, but the latter overcame the first in most of the syndromic scales. Adolescents without romantic relation scored higher in the psycho-social competencies than those who enjoyed romantic relation, although the second ones showed more psychopathology than the first ones. Finally, working (in addition to studying) did not seem to be relevant in determining differences regarding the psychosocial competencies and syndromic scales. In a recent study conducted by Musitu, Suarez, \& Del Moral (2015) with a sample of 2,399 Spanish adolescents, it was observed that, usually, styles of socialization more related to school violence and its different dimensions were, in the positive direction, authoritarian and neglectful. Inversely, the authoritative and indulgent ones, being the indulgent style the one with the highest correlation coefficient.

In conclusion, the present study shows seven first-order common factors in both, boys and girls: Anxious/Depressed, Somatic Complaints, Delinquent Behavior, Aggressive Behavior, Attention Problems, Thought Problems and Relational Problems. Also, a single second-order factor in younger males appear when factoring of these seven syndromes and older males and females showed labeled internalize and externalize symptoms, resembling the results obtained in former studies with Spanish population.

\section{Acknowledgements}

This study was conducted on collaboration between the Clinical and Health Psychology Department of Granada (Spain) University and the Induction Department of Sakhnin College (Israel), and supported by the Spanish Agency of International Cooperation.

\section{References}

Abad, J., Forns, M., Amador, J. A., \& Martorell, B. (2000). Fiabilidad y validez del youth self report en una muestra de adolescentes. Psicothema, 12, 49-54.

Achenbach, T. M. (1978). The child behavior profile, I: Boys aged 6-11. Journal of Consulting and Clinical Psychology, 46, 478-488. https://doi.org/10.1037/0022-006X.46.3.478

Achenbach, T. M. (1991a). Manual for the Child Behavior Checklist/4-18 and 199 profile. Burlington, TV: University of Vermont, Department of Psychiatry.

Achenbach, T. M. (1991b). Manual for the Self-Report and 1991 YSR profile. Burlington, TV: University of Vermont, Department of Psychiatry.

Achenbach, T. M. (1991c). Manual for the Teacher's Report Form and 1991 TRF profile. Burlington, TV: University of Vermont, Department of Psychiatry.

Achenbach, T. M., \& Rescorla, L. A. (2000). Mental health practioners' guide for the Achenbach System of Empirically Based Assessment (ASEBA). Burlington, VT: University of Vermont Department of Psychiatry.

Achenbach, T. M., \& Rescorla, L. A. (2001). Manual for the ASEBA School. Age Forms \& Profiles. Burlington, VT: University of Vermont, Research Center for Children, Youth \& Families.

Achenbach, T. M., Dumenci, L., \& Rescorla, L. A. (2001). Ratings of Relations between DSM-IV Diagnostic Categories and Items of the CBCL/6-18, TRF, and YSR. Burlington, TV: University of Vermont, Research Center for Chidren, Youth, and Families. Recuperado el 22 de Abril de 2001 de www.ASEBA.org

American Psychiatric Association. (2000). Diagnostic and statistical manual of mental disorders, (4th ed., text revision). Washington, DC: American Psychiatric Association.

American Psychiatric Association. (2014). Diagnostic and statistical manual of mental disorders, (5th ed.). Washington, DC: American Psychiatric Association.

Baldwin, A. L. (1955). Behavior and development in childhood. New York: Dryden.

Barber, B. K., Chadwick, B. A., \& Oerter, R. (1992). Parental behaviors and adolescent selfesteem in the United-States and Germany. Journal of Marriage and the Family, 54, 128-141. https://doi.org/10.2307/353281 
Baumrind, D. (1971). Current theories of parental authority. Developmental Psychology Monographs, 4(1, part 2), 1-103. https://doi.org/10.1037/h0030372

Baumrind, D. (1983). Rejoinder to Lewis reinterpretation of parental firm control effects: Are authoritative families really harmonious? Psychological Bulletin, 94, 132-142. https://doi.org/10.1037/0033-2909.94.1.132

Baumrind, D. (1991). Parent styles and adolescent development. In J. Brooks-Gunn, R. Lerner, \& A. C. Petersen (Eds.). The encyclopedia of adolescence (pp. 746-758). New York: Garland.

Becker, W. C. (1964). Consequences of different kinds of parental discipline. In M. L. Hoffman, \& L. W. Hoffman (Eds.), Review of Child Development Research (Vol. 1, pp. 169-208). New York: Russell Sage Foundation.

Carretero-Dios, H., \& Pérez, C. (2007). Standards for the development and review of instrumental studies: Considerations about test selection in psychological research. International Journal of Clinical and Health Psychology, 7, 863-882.

Cava, M. J., \& Musitu, G. (2002). La convivencia en la escuela. Barcelona: Paidós.

Chao, R. K. (2001). Extending research on the consequences of parenting style for Chinese Americans and European Americans. Child Development, 72(6), 1832-1843. https://doi.org/10.1111/1467-8624.00381

Christian, D. L. (2002). The effects of parenting styles on the development of adaptative competencies and reduction in problem behavior among children with and without visual impairments and blindness. Dissertation Abstracts, International Section B: The Sciences and Engineering, 62(7-B): 3398.

Cruz, D., Narciso, I., Pereira, C. R., \& Sampaio, D. (2014). A Short Form of the Portuguese Version of the Youth Self-Report. Journal of Child and Family Studies, 23(6), 1114-1127. https://doi.org/10.1007/s10826-013-9770-x

DiMaggio, R., \& Zappulla, C. (2014). Mothering, fathering, and Italian adolescents'problem behaviors and life satisfaction: Dimensional and typological approach. Journal of Child and Family Studies. https://doi.org/10.1007/s10826-013-9721-6

Dornbusch, S. M., Ritter, P. L., Leiderman, P. H., Roberts, D. F., Fraleigh, M. J. (1987). The relation of parenting style to adolescent school performance. Child Development, 58, 1244-1257. https://doi.org/10.2307/1130618

Ebesutani, C., Bernstein, A., Martinez, J. I., Chorpita, B. F., \& Weisz, J. R. (2011). The Youth Self-Report: Applicability and validity across younger and older youths. Journal of Clinical Child and Adolescent Psychology, 40, 338-346. https://doi.org/10.1080/15374416.2011.546041

Ferdinand, R. F. (2007). Predicting anxiety diagnoses with the Youth Self-Report. Depression and Anxiety, 24, 32-40. https://doi.org/10.1002/da.20186

Ferro, M. A., Boyle, M. H., Scott, J. G., \& Dingle, K. (2014). The Child Behavior Checklist and Youth Self-Report in adolescents with epilepsy: testing measurement invariance of the Attention and Thought Problems subscales. Epilepsy \& Behavior, 31, 34-42. https://doi.org/10.1016/j.yebeh.2013.11.009

Foxcroft, D. R., \& Lowe, G. (1991). Adolescent drinking behaviour and family socialization factors: A meta-analysis. Journal of Adolescence, 14, 255-273. https://doi.org/10.1016/0140-1971(91)90020-R

Fuentes, M. C, García, J. F., Gracia, E., \& Alarcón, A. (2015). Parental socialization styles and psychological adjustment: A study in Spanish adolescents. Revista de Psicodidáctica, 20.

Garaigordobil, M. (2003). Intervención psicológica para desarrollar la personalidad infantil. juego, conducta prosocial y creatividad. [Psychological intervention for developing children's personality, play, prosocial behavior and creativity] (Vol. 1). Madrid, Spain: Pirámide.

Garaigordobil, M. (2008). Intervención psicológica con adolescentes. Un programa para el desarrollo de la personalidad y la educación en derechos humanos [Psychological intervention with adolescents. A program for the development of personality and education in human rights] (2nd ed.). Madrid, Spain: Pirámide. (Original work published 2000)

García, M. V., \& Palos, P. A. (2005). Validez del Youth Self Report para problemas de conducta en niños mejicanos. International Journal of Clinical and Health Psychology, 5, 499-520.

Geibel, S., Habtamo, K., Mekonnen, G., Jani, N., Kay, L., Shibru, J., Bedilu, L., \& Kalibala, S. (2016). Reliability and Validity of an Interviewer-Administered Adaptation of the Youth Self-Report for Mental Health Screening of Vulnerable Young People in Ethiopia. PLoS One, 11(2), e0147267. https://doi.org/10.1371/journal.pone.0147267

González, L. L., \& Cueto, E. G. (2000). El rendimiento escolar y los trastornos emocionales y comportamentales. Psicothema, 12, 340-343.

Harman, H. H. (1980). Análisis factorial moderno. Madrid: Saltés. (Original, 1976). 
Ibabe, I., \& Jaureguizar, J. (2010). Child-to-parent violence: Profile of abusive adolescents and their families. Journal of Criminal Justice, 38(4), 616-624. https://doi.org/10.1016/j.jcrimjus.2010.04.034

Ivanova, M. Y., Achenbach, T. M., Rescorla, L. A., Dumenci, L., Almqvist, F., Bilenberg, N., ... Verhulst, F. C. (2007). The generalizability of the Youth Self-Report syndrome structure in 23 Societies. Journal of Consulting and Clinical Psychology, 75, 729-738. https://doi.org/10.1037/0022-006X.75.5.729

Jordan, P. E., Rescorla, L. A., Althoff, R. R., \& Achenbach, T. M. (2016). International comparisons of the Youth Self-Report Dysregulation Profile: Latent class analyses in 34 societies. Journal of American Academy of Child and Adolescent Psychiatry, 55, 1046-1053. https://doi.org/10.1016/j.jaac.2016.08.012

Kirchner, T., Forns, M., \& Amador, J. A. (2006). Eighteen-month test-retest stability of the Youth Self Report in a sample of Catalonian adolescents. Psychological Reports, 99(2), 635-640. https://doi.org/10.2466/pr0.99.2.635-640

Lacalle, M., Domènech, J. M., Granero, R., \&, Ezpeleta, L. (2014). Valifity of the DSM-Oriented Scales of the Child Behavior Checklist and Youth Self-Report. Psicothema, 26(3), 364-371.

Lambert, M. C., Essau, C. A., Schmitt, N., \& Samms-Vaughan, M. E. (2007). Dimensionality and psychometric Invariance of the Youth Self-Report Form of the Child Behavior Checklist in cross-national settings. Assessment, 14, 231-245. https://doi.org/10.1177/1073191107302036

Laurin, J., Wallace, C., Draca, J., Aterman, S., \& Tonmyr, L. (2018). Youth self-report of child maltreatment in representative surveys: a systematic review. Health Promotion and Chronic Disease Prevention in Canada, 38(2), 37-54. https://doi.org/10.24095/hpcdp.38.2.01

Lemos, S. G., Hidalgo, A. M., Calvo, P., \& Menéndez, P. (1992a). Estructura factorial de la prueba YSR y su utilidad en psicopatología infanto-juvenil. Análisis y Modificación de Conducta, 18, 883-905.

Lemos, S. G., Hidalgo, A. M., Calvo, P., \& Menéndez, P. (1992b). Salud mental de los adolescentes asturianos. Psicothema, 4, 21-48.

Lemos, S. G., Hidalgo, A. M., Calvo, P., \& Menéndez, P. (1992c). Validación de la escala de psicopatología infanto-juvenil YSR. Clínica y Salud, 3, 183-194.

Lemos, S. G., Vallejo, G. S., \& Sandoval, M. M. (2002). Estructura factorial del Youth Self-Report (YSR). Psicothema, 14, 816-822.

Lewis, C. C. (1981). The effects of parental firm control: A reinterpretation of the findings. Psychological Bulletin, 90, 547-563. https://doi.org/10.1037/0033-2909.90.3.547

Linares, M. C. G., Rusillo, M. T. C., de la Torre Cruz, M. J., de la Villa Carpio Fernández, M., \& Arias, P. F. C. (2011). Prácticas educativas paternas y problemas internalizantes y externalizantes en adolescentes españoles [Parenting practices and internalizing and externalizing problems in Spanish adolescents]. Psicothema, 23(4), 654-659.

Martínez, B. (2013). El mundo social del adolescente: amistades y pareja. In E. Estévez (coord.), Los problemas en la adolescencia: respuestas y sugerencias para padres y educadores (pp.71-96). Madrid: Síntesis.

Montero, I., \& León, O. G. (2007). A guide for naming research studies in Psychology International Journal of Clinical and Health Psychology, 7, 847-862.

Musitu, G., \& Cava, M. J. (2001). La familia y la educación. Barcelona: Octaedro.

Musitu, G., Suárez-Relinque, C., \& Del Moral, G. (2015). Estilos de socialización parental y violencia escolar en adolescentes. Psychosocial Intervention.

O'Keefe, M., Mennen, F., \& Lane, C. J. (2006). An examination of the factor structure for the Youth Self Report on a multiethnic population. Research on Social Work Practice, 16, 315-325. https://doi.org/10.1177/1049731505285340

Rosso, B. B., \& Helena, M. A. (2017). Contribuição dos Indicadores de Problemas Emocionais e de Comportamento para o Rendimento Escolar. Revista Colombiana de Psicología, 26(2), 283-294. https://doi.org/10.15446/rcp.v26n2.59813

Sainero, A., del Valle, J., \& Bravo, A. (2015). Detección de problemas de salud mental en un grupo especialmente vulnerable: niños y adolescentes en acogimiento residencial. Anales de Psicología, 31(2), 472-480. https://doi.org/10.6018/analesps.31.2.182051

Sandoval, M. M., Lemos, S. G., \& Vallejo, G. S. (2006). Self-reported competences and problems in Spanish adolescents: A normative study of the YSR. Psicothema, 18, 804-809.

Schaefer, E. S. (1959). A circumplex model for maternal behavior. Journal of Abnormal and Social Psychology, 59, 
226-235. https://doi.org/10.1037/h0041114

Sears, R. R., Maccoby, E. E., \& Levin, H. (1957). Patterns of child rearing. Evanston, IL: Row, Peterson.

Smetana, J. G. (1995). Parenting styles and conceptions of parental authority during adolescence. Child Development, 66, 299-315. https://doi.org/10.2307/1131579

Steinberg, L., Lamborn, S. D., Dornbusch, S. M., \& Darling, N. (1992). Impact of parenting practices on adolescent achievement: Authoritative parenting, school involvement, and encouragement to succeed. Child Development, 63, 1266-128. https://doi.org/10.2307/1131532

Steinberg, L., Mounts, N. S., Lamborn, S. D., \& Dornbusch, S. M. (1991). Authoritative parenting and adolescent adjustment across varied ecological niches. Journal of Research on Adolescence, 1, 19-36.

Toros, F., Özge, A., Kütük, M. Ö., Kaleagasi, H., Kanık, A., \& Örekici, T. G. (2010). The Contribution of Youth Self-Report (YSR) in the Diagnosis of Psychiatric Comorbidity of Juvenile Primary Headache Disorders. Journal of Neurological Sciences (Turkish), 27(2), 127-138.

Undheim, A. M., Wichstrom, L., \& Sund, A. M. (2011). Emotional and Behavioral Problems among School Adolescents with and without Reading Difficulties as Measured by the Youth Self-Report: A One-Year Follow-Up Study. Scandinavian Journal of Educational Research, 55(3), 291-305. https://doi.org/10.1080/00313831.2011.576879

Verhulp, E. E., Stevens, G. W. J. M., Van de Schoot, R., \& Vollebergh, W. A. M. (2014). Using the Youth Self-Report internalizing syndrome scales among ethnic minority and majority groups: Testing measurement invariance across ethnic groups and over time. European Journal of Developmental Psychology, 11, 102-110. https://doi.org/10.1080/17405629.2013.806263

Verhulst, F. C., Van der Ende, J. Y., \& Koot, H. M. (1997). Handleiding voor de Youth Self-Report (YSR) \{Manual for the Youth Self-Report\}. Rotterdam, the Netherlands: Erasmus University/Sophia Children's Hospital.

Wyss, A. C., Voelker, L. S., Cornock, L. B., \& Hakim-Larson, J. (2003). Psychometric properties of a French-Canadian translation of Achenbach's Youth Self-Report. Canadian Journal of Behavioural Science, 35, 67-71. https://doi.org/10.1037/h0087189

Yates, K. F., Larr, A. S., Sweat, V., Maayan, L., Siegel, S. C., \& Convit, A. (2014). Hispanic youth with excess weight display psychological distress: do the youth self-report norms accurately capture this phenomenon? Hispanic Journal of Behavioral Sciences, 36(2), 195-210. https://doi.org/10.1177/0739986314522111

Zubeidat, I., Fernández-Parra, A., Sierra, J. C., \& Salinas, J. M. (2008). Evaluación de los factores de riesgo asociados a la ansiedad social y a otras psicopatologías en adolescentes españoles. Salud Mental, 31, 189-196.

Zubeidat, I., Fernández-Parra, A., Sierra, J. C., Vallejo, M. A., \& Ortega, J. (2009). Características psicosociales y psicopatológicas en adolescentes españoles a partir del Youth Self-Report/11-18. Anales de Psicología, 25, 60-69.

\section{Copyrights}

Copyright for this article is retained by the author(s), with first publication rights granted to the journal.

This is an open-access article distributed under the terms and conditions of the Creative Commons Attribution license which permits unrestricted use, distribution, and reproduction in any medium, provided the original work is properly cited. 